\title{
El mundo al revés: revisión del concepto y análisis de su operatividad en las prácticas escénicas de los siglos XVII Y XVIII

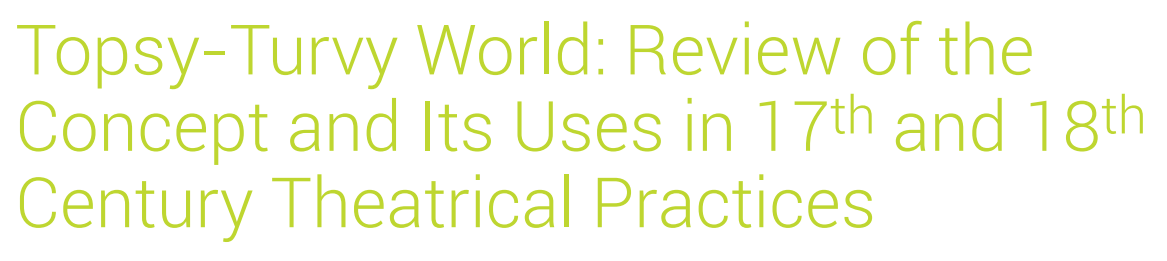

\section{Álvaro Ceballos Viro}

Université de Liège

BÉLGICA

a.ceballosviro@uliege.be

[Hipogrifo, (issn: 2328-1308), 8.1, 2020, pp. 11-31]

Recibido: 20-09-2019/ Aceptado: 03-10-2019

DOI: http://dx.doi.org/10.13035/H.2020.08.01.03

Resumen. La categoría del mundo al revés es bien conocida en historia cultural, pero demasiado a menudo se hace de ella un uso intuitivo, considerándola tan pronto un tema, tan pronto un motivo, y asociándola rutinariamente con «lo carnavalesco». Tras revisar la configuración del mundo al revés como un objeto cultural históricamente determinado, el presente estudio identifica en él un funcionamiento retórico específico, consistente en la exposición paratáctica de motivos paradójicos dentro de una macroestructura descriptiva. Esta definición precisa hace aflorar diferencias sutiles entre obras que, de otro modo, podían dar la impresión de responder a planteamientos idénticos, y subraya importantes cambios estéticos que podrían pasar desapercibidos. A partir de esa definición, se explicará por qué el teatro breve constituye un marco genérico idóneo para esta modalidad de la ficción, y se discutirá la vinculación que se ha establecido tradicionalmente entre el mundo al revés, el carnaval y el mito de Jauja.

Palabras clave. Teatro breve; mojigangas; narratología; modalidad; antífrasis; carnaval; Jauja. 
Abstract. The topsy-turvy world is a well-known concept in cultural history. However, it is often used in an intuitive way, considered to be either a theme or a motif and usually associated with «the carnivalesque». After tracing the gradual appearance of the topsy-turvy world as a historically determined cultural object, this study examines its specific rhetorical fabric, consisting of the paratactic exposition of paradoxical motifs in a descriptive macrostructure. This precise definition brings out subtle differences between works that might otherwise seem to be identical, and underscore major aesthetic changes that could go unnoticed. This will allow us to better understand the suitability of comical interludes for this form of fiction but also to question the topical link established between the topsy-turvy world, carnival and the myth of Cockaigne.

Keywords. World upside-down, Entr'actes, mojiganga, Narratology, Modes, Antiphrasis, Carnival, Cockaigne.

Una mojiganga de Calderón saca a escena a un francés que, mediante un mundinovi o titilimundi, muestra a dos mujeres varias imágenes de un orden trastocado, de un universo en el que las relaciones lógicas se han invertido. Como explica dicho francés, llamado extrañamente Jusepe, los habitantes de ese lugar

\begin{tabular}{ll} 
& {$[. .$.$] tienen un adbitrio$} \\
& con que se mueren de viejos \\
¿Qué adbitrio es? & \multicolumn{1}{c}{ Que los dotorres } \\
JUSERAREA & no curan a los enfermos. \\
LAS DOS & Pues, ¿quién los cura? \\
JUSEPE & Sus mulas, \\
& a quien ellos traen a cuestos ${ }^{7}$.
\end{tabular}

El asno médico y el hombre que sirve de montura son dos elementos frecuentes de un tipo de representación que conocemos como «el mundo al revés»; un tipo de representación que ha sido estudiado más sistemáticamente por la iconología que por la retórica, y cuyos referentes plásticos son más conocidos que los literarios. El mundo al revés ha sido objeto de importantes trabajos de conjunto, como los de Cocchiara, Tristan, Donaldson, Babcock, Jean Lafond y Agustín Redondo. Ninguno de ellos habría sido igual si Ernst Robert Curtius no hubiera escrito sobre este asunto unas páginas clarividentes².

Algunas de las formulaciones literarias más interesantes y conocidas del mundo al revés en el ámbito hispánico las hallamos en el teatro menor, en un reducido corpus de piezas que ya han sido parcialmente estudiadas por Helen Grant, Miguel Zugasti, Catalina Buezo, Ramón Martínez, Fernando Plata y Francisco Sáez Rasposo; entre ellas, dos mojigangas de Quiñones de Benavente, otra de Calderón y

1. Sigo la edición de Plata Parga, 2009, p. 189.

2. Curtius, 1956, pp. 117-130. 
algunas de autor desconocido. La adscripción de esas piezas al «mundo al revés» se presenta invariablemente como transparente y apodíctica. Mi propósito en estas páginas será demostrar que la retórica de la inversión no tiene el mismo funcionamiento en todas esas obras, y en otras que añadiré a este interesante subcorpus teatral. Para ello, se hará necesario establecer una definición más rigurosa y nítida tanto de los atributos retóricos como de las particularidades pragmáticas de ese artefacto cultural que conocemos como «mundo al revés».

\section{CONSOLIDACIÓN INTERNACIONAL DEL CONCEPTO DEL «MUNDO AL REVÉS»}

En varias parodias goliárdicas, en ciertos pasajes de Aucassin et Nicolette y en algunas baladas como la de las contradictions de Villon reconocemos ya el procedimiento de inversión funcional del mundo al revés ${ }^{3}$. Tal reconocimiento es, sin embargo, retrospectivo: el mundo al revés no es una constante histórica, sino el resultado de la multiplicación de xilografías con motivos de inversión desde mediados del siglo XVI; estos grabados alcanzaron una gran difusión en toda Europa y se titulaban -en distintos idiomas y con ligeras variaciones - «el mundo al revés». Ha solido considerarse que el primero era Cosi va il mondo alla riversa, una lámina italiana fechada en $1560^{4}$. En el mismo sentido se pronunciaba Hilário Franco Júnior: «c'est entre 1555 et 1560, non seulement en Hollande, mais aussi en Italie et en Allemagne, que naquit une véritable iconographie du monde à l'envers» ${ }^{5}$. Sin embargo, ya en la década de 1540 el artista florentino Francesco Salviati había pintado una serie de ilustraciones a la acuarela «presumibilmente destinata ad illustrare un libro sul "Mundus Inversus"»6. En las acuarelas de Salviati encontramos inversiones atingentes, entre otros, a los órdenes de edad, jerarquía, ecosistema, depredación y roles de género.

Resulta elocuente que la estampa de Frans Hogenberg conocida como La capa azul (Die blau Huicke), en circulación desde 1558, fuera presentada en versiones posteriores con el título de El mundo al revés ${ }^{7}$. Hogenberg daba allí una forma plástica a varios proverbios holandeses, como es fama que haría Pieter Bruegel muy poco tiempo después: también su cuadro La locura del mundo (llamado en otras ocasiones Proverbios holandeses o La capa azul) sería identificado a finales del siglo XVII como «Le Monde Renversé, représenté par plusieurs Proverbes et Moralités» ${ }^{9}$. Ambos casos prueban que la tradición de proverbios ilustrados estaba releyéndose a la luz de una nueva estructura, más familiar. Tan familiar que en 1584 Juan Rufo hablaba de ella con gran naturalidad y como si contuviera motivos por todos conocidos: «Quien el mundo al revés pintar procura / no trace cosas ya des-

3. Véase, respectivamente, Trousson, 1989, pp. 18-22; Delpech, 1979, p. 37; Curtius, 1956, p. 117-119; Franco Júnior, 2013, pp. 66-67; Dutli, 2010, pp. 133-134.

4. Chartier y Julia, 1976, p. 44.

5. Franco Júnior, 2013, p. 334; véase también Kunzle, 1977, p. 198.

6. Salviati, 1992, 7.

7. Cocchiara, 2007, p. 221 e il. 14.

8. Cocchiara, 2007, pp. 219-220.

9. Kunzle, 1977, p. 198 y 1978, pp. 71-74. 
comunales, / no finja peces en la tierra dura, / ni en el undoso mar los animales; / dibuje este desorden y locura, / y hará que se admiren los mortales» ${ }^{10}$.

Hacia 1570 comenzó la larga andadura de II mondo alla riversa, de Ferrando Bertelli, una estampa que sería imitada en distintas lenguas durante el siglo XVII ${ }^{11}$. Ewout Muller inauguraría todavía en el siglo XVI la disposición de rejilla que caracteriza a los pliegos de aleluyas contemporáneos sobre el mundo al revés ${ }^{12}$. Bien entrado ya el siglo XVII se imprimen en Alemania los grabados Die widersinnige Welt, de Jacob van der Heyden -basados en una canción de Hans Sachs de 1531-, así como los de Paulus Fürst: Die widerwertige Welt y Die verkehrte Welt ${ }^{13}$. En Francia, en esa misma época, Jean Ganière hizo imprimir El mondo al revés, una versión fiel del grabado de Bertelli, con título y pies en castellano ${ }^{14}$, de la que Honervogt sacó en Colonia una copia prácticamente idéntica ${ }^{15}$.

Desde 1698 y durante casi tres décadas saldrían de los tórculos parisinos de los Bonnart innumerables xilografías del mundo al revés (1698-1726), mientras en Ámsterdam se reproducía un pliego de aleluyas titulado De verkeerde Wereld, cuyo pie rezaba «J. Noman \& Zalt-Bommel» ${ }^{16}$. Les siguieron, ya en el siglo XVIII, Il mondo al rovescio ossia il costume moderno de los Remondini (con versiones españolas) ${ }^{17}$ y las estampas de Jacques Chiquet, Pierre Gallays, Mondhard, Rabier Boulard, Isaac van Putte, Joannes Kannewet y muchos otros ${ }^{18}$.

En el XIX el mundo al revés sería representado en numerosísimos pliegos de aleluyas impresos por Agustín Laborda, Ildefonso Mompié, Ignacio Estivill, José Clara, Antonio Bosch, Pablo Roca o José María Marés ${ }^{19}$. No obstante, querría cerrar este recuento en 1799, cuando sale de las prensas la primera edición de los Caprichos de Goya. Varias de sus láminas retoman los motivos de aquellos mismos grabados: el adulto niño (núm. 4), la silla que se sienta sobre la mujer (núm. 26) ${ }^{20}$, el discípulo que sabe más que el maestro (núm. 37), el médico ignorante (núm. 40), el burro que cabalga sobre un hombre (núm. 42)... El marido que tiene la madeja de lana (núm. 73) recuerda poderosamente al hombre que hila, otro de los motivos más tradicionales del mundus inversus; también el seminario de burros (núm. 49) o la feminización del varón bajo el imperio de la mujer en «Le descañona» (núm. 35) podrían traer a la memoria módulos consagrados ${ }^{21}$.

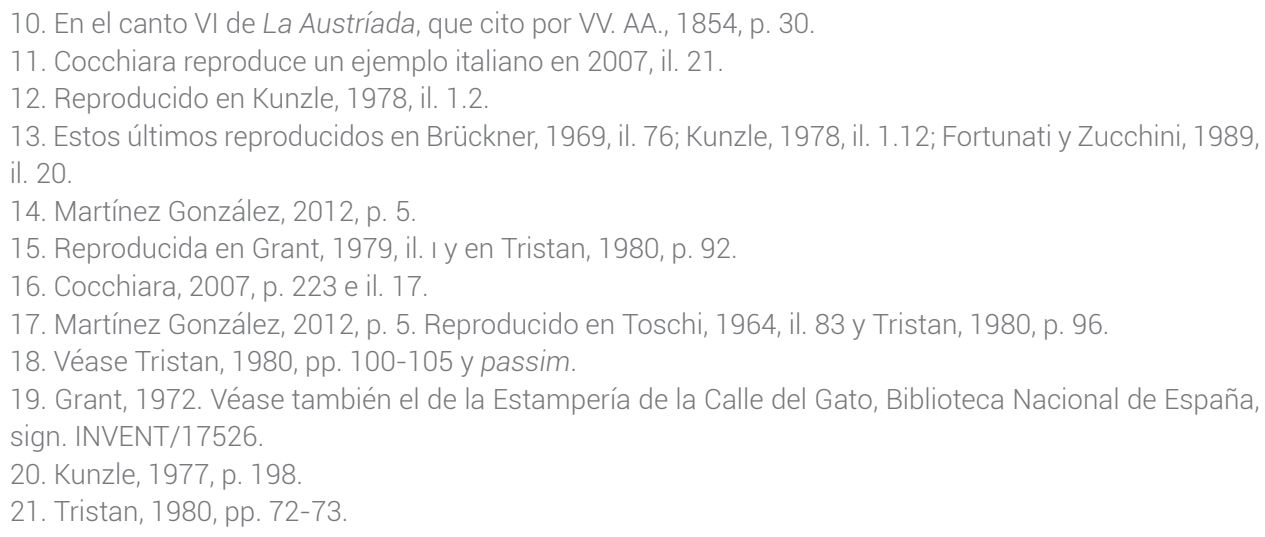




\section{ORÍGENES DEL «MUNDO AL REVÉS» EN ESPAÑA}

Estos grabados modernos no hacían sino adaptar a la reproducción gráfica un dispositivo discursivo que la literatura conocía bien. Ya a principios del siglo XIV Juan Ruiz exponía con una coherencia sorprendente cómo el amor y el dinero habían hecho que el mundo quedase «revuelto» y «mudado», y acumulaba motivos similares a los de la tradición iconográfica de la estampa popular: idiotas sabios, cojos veloces, nobles villanos, culpables indultados, mudos locuaces, viejos rejuvenecidos, etc. Las páginas en las que el arcipreste de Hita describe esos trastornos merecen comentario aparte; baste aquí señalar que dialogan con poemas goliárdicos como «Florebat olim studium», «In Gedeonis area» 220 «In terra summus rex est hoc tempore nummus».

En la suscriptio de uno de los emblemas de Juan de Horozco y Covarrubias podía leerse: «El mundo está trocado, no lo entiendo, / [...] La liebre tras el galgo va corriendo, / y el ratón tras el gato» ${ }^{23}$ (1589). Su pictura ostenta, en dos círculos concéntricos, liebres y perros, gatos y ratones que se persiguen respectivamente unos a otros.

«Mundo revuelto», «mundo trocado»: los sintagmas que emplean Juan Ruiz y Covarrubias a 250 años de distancia sugieren convincentemente la gestación en la moyenne durée de una nueva forma de inversión simbólica que difiere de manera sustancial y fácilmente objetivable de los impossibilia y adynata presentes en varios clásicos grecolatinos ${ }^{24}$. David Kunzle observó con mucho tino que en los grabados modernos que representan el mundo al revés «[t]he natural and social impossibilities [...] are no longer used as discrete rhetorical and metaphorical figures, like the "adynata" of ancient and medieval texts, but for their own sakes» ${ }^{25}$. Lo mismo puede decirse de los textos castellanos mencionados, así como de muchos otros de la España del XVII que, aunque no siempre se identifiquen explícitamente mediante etiquetas como las de «mundo al revés», «trocado» o «revuelto», actualizaban el mundo al revés como un estado presente, efectivo (o inevitable), retóricamente autónomo, y no como un término de comparación hiperbólico.

Francisco de Quevedo, por ejemplo, operaría esa actualización mediante una artimaña alegórica consistente en imaginar un Juicio Final pagano: en La hora de todos y la Fortuna con seso (1628-1639), los hombres acusan a la Fortuna de ha-

22. Curtius, 1956, pp. 117, 119 y 122; Cocchiara, 2007, pp. 111-112.

23. Es el que hace el núm. 79 de la tercera centuria. Lo comentaron Helen F. Grant (1979, p. 28) e Isabel Mateo Gómez (en Gutiérrez Baños, 1997, p. 148). Stoichita y Corderich destacan otro emblema, el 64. de la segunda centuria, cuyo lema es «nevtrvmque et vtrvmque»: «Soy varón, soy mujer, soy un tercero, / que no es uno ni otro, ni está claro / cuál destas cosas sea», «monstro horrendo y raro» que se endereza al final contra los afeminados (2016, pp. 71-72; en esta y en otras citas modernizo las grafías sin relevancia fonológica).

24. Para una definición del hiperónimo «inversión simbólica» véase Babcock, 1978, p. 14.

25. Kunzle, 1977, p. 198. 
berlo puesto todo al revés, y Júpiter decreta que durante una hora cada cual reciba lo que merece, lo que da lugar a cuarenta escenas de inversión ${ }^{26}$.

Menos conocidos que los sueños quevedescos son los Dos discursos del mundo al revez y claro desengaño de Cosme Gómez de Tejada (1641). En el primero de ellos, los animales constatan la distancia inconmensurable que media entre la sociedad de su época y la de la Edad de Oro. El narrador les propone a los lectores que lo acompañen para que «todo al revez lo vea[n] trocado». En el segundo discurso, los dioses del Olimpo debaten sobre la situación de la Tierra y en particular sobre la decadencia militar; se deplora allí que «los más fieros soldados» hayan devenido en ninfas, que las naciones hayan «troca[do] con el uso / la espada más noble en rueca / [...] y acá estos hermafroditas / mujeres, en cabelleras, / y por gala, con bigotes / los dos sexos represent[e]n» ${ }^{27}$.

Diez años más tarde se publicó la primera parte de El Criticón, de Baltasar Gracián; como explica Agustín Redondo, la obra se encuentra atravesada por una conciencia aguda de que el mundo ha caído en un estado de desorden ${ }^{28}$, pero es en el capítulo sexto, dedicado a la capital de España, donde más claramente se acumulan los motivos antifrásticos que reconocemos como un mundo al revés. Pululan allí personas que andan patas arriba, otras que caminan hacia atrás, mujeres viriles, hombres afeminados, ciegos que guían a los que ven y médicos que hacen enfermar a los sanos; muchos se levantan cuando se debían acostar; quienes mandan son esclavos de sus apetitos, mientras que quienes son señores de sí mismos deben someterse y humillarse. Uno de los protagonistas de ese viaje alegórico, el centauro Quirón, concluye que «anda el mundo al revés»:

va al revés en consecuencia de aquel desorden capital [de los apetitos]: la virtud es perseguida, el vicio aplaudido; la verdad muda, la mentira trilingüe; los sabios no tienen libros, y los ignorantes librerías enteras; los libros están sin doctor, y el doctor sin libros; la discreción del pobre es necedad, y la necedad del poderoso es celebrada; los que habrían de dar la vida, matan; los mozos se marchitan, y los viejos reverdecen $[. . .]^{29}$.

No deben asimilarse inmediatamente las utopías a este mismo dispositivo: la utopía propone una sociedad plausible, sometiéndose «ad imperativi di credibilità e di verosimiglianza che preoccupano assai poco il mondo alla rovescia»30. Pese a todo, creo que la popularidad de esa matriz de inversiones simbólicas que conocemos como «mundo al revés» imprime su huella en alguna utopía, como la de ese manuscrito anónimo de 1682 en el que se nos describe un país imaginario llamado

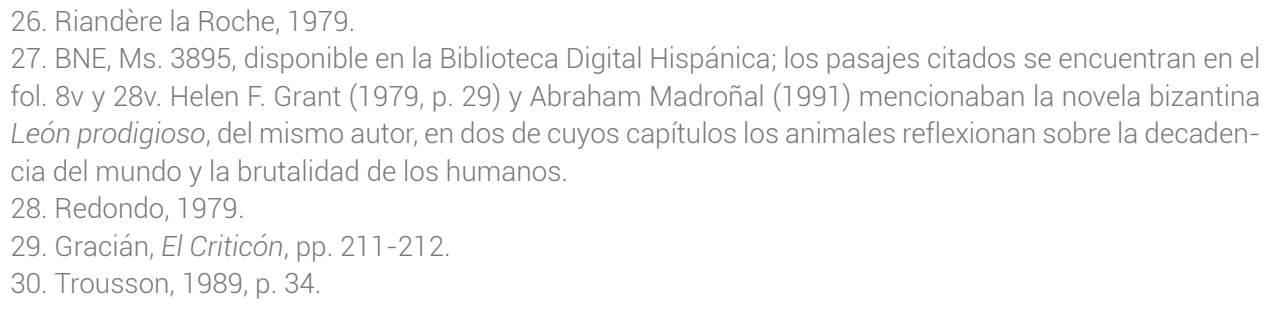


Sinapia ${ }^{31}$. La cartografía de Sinapia corresponde a la de la península ibérica puesta de medio lado, y su nombre es un anagrama fonético de Hispania. En Sinapia no existen la propiedad privada ni la moneda; su geografía política es perfectamente racional y sistemática; la forma del Estado es allí una desconcertante república monárquica. Si las utopías suelen proyectar la esperanza de una sociedad diferente, opuesta en varios aspectos a aquella en la que vivimos, Sinapia subraya la antítesis y ubica ese paraíso en las antípodas de Europa.

Ian Donaldson nos ofrece otros ejemplos de obras británicas de finales del XVI y principios del XVII en las que tierras remotas son escenario de costumbres contrarias a las occidentales ${ }^{32}$. Se demora en The Antipodes, de Richard Brome (1638), donde por medio de un ardid metateatral se hace creer a un personaje que ha llegado al polo opuesto del globo. Allí

the people govern the magistrate, children and servants command their parents and masters, the women rule the men [...]. Old men marry young girls, young boys marry old women, the conventions of courtship and even of sexual intercourse are reversed [...]. Parrots teach their mistresses to talk; wild animals are hunted by tame animals; lawyers are hones; and the actors are all Puritans ${ }^{33}$.

Se diría que esta farsa es una adaptación escénica de los grabados que, para entonces, como sabemos, circulaban profusamente por Europa. Donaldson menciona asimismo los mundos al revés convocados en pasajes más breves de Jonathan Swift y Alexander Pope, entre otros ${ }^{34}$. Aberraciones como estas tampoco eran extrañas al teatro de títeres británico, donde encontramos diablos asesinados o verdugos ajusticiados ${ }^{35}$.

Como puede apreciarse, entre el Libro de buen amor y Sinapia surgen y se multiplican las alusiones y formulaciones literarias del mundo al revés, tanto en España como en otros países. Será en el teatro de la Edad Moderna donde más y mejores testimonios de este tipo de representación encontremos. Pero antes de abordar el teatro debemos resolver un interrogante teórico que no suele ponerse sobre la mesa: ¿cuáles son las características definitorias del mundo al revés y a qué capítulo de la poética pertenece?

\section{PROPUESTA de UNA DEFINICIÓN RETÓRICA DEL MUNDO AL REVÉS}

La crítica ha tratado el mundo al revés unas veces como tema, otras como motivo, otras como un tópico; las denominaciones llegan a emplearse indiscrimina-

31. Editado por Avilés Fernández, 1976.

32. Donaldson, 1970, pp. 85-86.

33. Donaldson, 1970, p. 89.

34. Donaldson, 1970, pp. 22 y 186

35. Caillois, 1967, p. 168. Podrían añadirse otros textos continentales del siglo XVII, como la oda XLIX de Théophile de Viau (c. 1623) o la comedia Von der verkehrten Welt, de Christian Weise (1683); para esta última, véase Kunzle, 1978, p. 79. 
damente incluso dentro de un mismo texto ${ }^{36}$. Es fácil constatar, sin embargo, que los documentos culturales que se presentan como mundos al revés pueden tratar de diferentes temas, compuestos a su vez de distintos motivos: el segundo de los Dos discursos de Gómez de Tejada, por ejemplo, trata de la decadencia del ejército; The Beggar's Oper de John Gay (1728) reúne varias situaciones de inversión bajo la isotopía general de la mendicidad. En cuanto a la noción de topos, Jean-Louis Dufays recomienda considerar dos acepciones, una clásica y otra más reciente: en la primera, nos hallaríamos ante una clase de argumentos retóricos, lo cual se compadece bien con la idea del adynaton como término de comparación, pero no tanto con el mundo al revés moderno; en la segunda acepción -localizable en Tzvetan Todorov, por ejemplo- topos vendría a ser una «configuración estable de motivos»; esto podría asimilarse al repertorio de módulos de inversión presentes en los mundos al revés, pero solo en apariencia, ya que esos motivos evolucionan y se renuevan de continuo, sin formar una «configuración estable» 37 .

Por lo demás, me parece evidente que, al manifestarse tan pronto en pintura como en poesía o en teatro, tampoco podemos considerar el mundo al revés como un género. Creo igualmente obvio que, a la vista de los contextos comunicativos en los que se difunde, el mundo al revés es una forma de ficción, y no puede confundirse con la mentira ni con la falsedad. No todo enunciado que contradiga literalmente la experiencia positiva es, pragmáticamente, una mentira ${ }^{38}$. Tampoco debería arrojarse el mundo al revés literario en ese cajón de sastre de la poesía absurda en el que a veces se han amontonado géneros bien definidos como los limericks, las canciones de comba y las fatrasies: hay en aquel una lógica, un código de representación sistemático del que estos últimos géneros, al menos en apariencia, carecen (fuera de cierta congruencia onírica o de las exigencias formales autoimpuestas). Las poesías de disparates y la chanson de fatras poseen cohesión sintáctica pero no coherencia temática. Del mundo al revés cabría decir más bien lo contrario: posee coherencia temática, pero es en las relaciones sintácticas donde se genera la paradoja. También habría que distinguirlo de la resverie medieval, que estaba constituida por dísticos coherentes pero incoherentemente vinculados a otros mediante una paradójica primera persona.

Quiero arriesgar aquí una definición de ese dispositivo ficcional que se desarrolla en la pintura y la literatura europeas de la Edad Moderna y que yuxtapone inversiones de relaciones reales. Comencemos sentando que el mundo al revés responde a una modalidad de representación poco sólita. Entiendo por «modalidad» de un texto literario la estrategia principal de interpretación a la que se presta.

36. Se refieren a él como tema (theme, thème) David Kunzle, 1977; Grant, 1979, p. 18; Redondo, 1979; Palla, 1992; Gutiérrez Baños, 1997; Pla Vivas, 1999. Lo identifican como tópico (topos) o motivo Curtius, 1956; Donaldson, 1970, p. 21; Grant, 1979, pp. 17 y 30; Trousson, 1989, p. 18; Menetti, 2002; Navarro Peiro, 2002; Zugasti, 2002; Silvestre Salamanca, 2004; Dorca, 2007; Martínez, 2007; Plata Parga, 2009; Gherardi, 2010. Leonardo Romero Tobar se refiere al mundo al revés como un «viejo principio satírico», con lo que circunda muy elegantemente el dilema de su clasificación retórica sin llegar a resolverlo (1996, p. 289). 
Es un sentido muy parecido al que le da Claudio Guillén a ese mismo término, y admite casi los mismos ejemplos, aunque yo preferiría verlo como una dimensión sustancialmente pragmática, más que temática o intertextual:

Es una modalidad, por ejemplo, la ironía, o la actitud irónica, o el narrar irónico [...]. Son modalidades de escritura, por ejemplo, utilizando adjetivos para mayor claridad, la modalidad satírica, o grotesca, o alegórica, o fantástica, o paródica, o realista. Estas modalidades califican, tiñen y orientan decisivamente los más distintos géneros ${ }^{39}$.

En la literatura del Siglo de Oro prima la modalidad alegórica, pues nos ofrece tipos morales que casi inevitablemente interpretaremos como símbolos o metáforas de cualidades abstractas (vicios o virtudes). La estética realista, más adelante, favorecerá una modalidad de representación que responde a la sinécdoque particularizante: la ficción presenta una serie de relaciones dialécticas entre familias, empleados, amantes, etc., que representan esas mismas relaciones a un nivel categorial superior (las clases socioprofesionales a las que aquellos pertenecen).

El mundo al revés, por su parte, se relaciona con la realidad conforme a una lógica antifrástica: el orden natural enunciado representa lo contrario del orden natural. Recordemos que la antífrasis es, en esencia, una figura retórica pragmática: cuando el significado literal es opuesto al significado real (es decir, al significado en un contexto dado). Corresponde, por lo tanto, a la acepción más frecuente - pero no única- de «ironía».

Tal y como se configura desde la Edad Media europea, esta modalidad de ficción antifrástica privilegia una construcción retórica precisa, consistente en la exposición paratáctica de motivos paradójicos en un objeto cultural descriptivo. Entiendo el adjetivo «paradójico», de acuerdo con su etimología, como referente a lo que contraría las ideas comunes o cierta forma de lógica ${ }^{40}$.

El hecho de que ese objeto cultural sea descriptivo, y no narrativo, favorece su representación plástica. De hecho, no tenemos costumbre de pensar como «mundo al revés» la práctica narrativa del modo antifrástico, que adoptan géneros por lo demás bien conocidos como la distopía o la historia alternativa ${ }^{41}$. La diferencia entre estas y el mundo al revés atañe únicamente al tipo de macrosecuencia discursiva seleccionada. Podríamos decir, por lo tanto, que lo que durante toda la Edad Moderna se denominó muy sistemáticamente «mundo al revés» eran ficciones descriptivas de modalidad antifrástica.

Rasgo característico de los textos descriptivos es estar compuestos por motivos intercambiables: el jinete cabalgado, el siervo que manda y la liebre que persigue al lebrel no cambian de significado si cambia el orden en el que se presentan. A estos motivos Giuseppe Cocchiara los llamó módulos, denominación que cuadra

39. Guillén, 2013, pp. 158-159.

40. Dupriez, 1984, pp. 318-319.

41. Los usos historiográficos de esta última pueden remontarse a Tito Livio, pero sus manifestaciones como ficción literaria no son anteriores al siglo XIX. 
muy bien al carácter descriptivo - modular, intercambiable, abierto- del mundo al revés, y que adoptaré en lo sucesivo.

El hecho de que el mundo al revés sea una suma de módulos explica algunas confusiones frecuentes. Hay módulos, como el del hombre que hila, tan ubicuos y tan antiguos que su evocación aislada convoca de manera inmediata y casi emblemática el imaginario del mundo al revés. Pero la auténtica dificultad radica en que no todos los módulos del mundo al revés son igual de imposibles, sino que unos son más imposibles que otros (y de hecho en neerlandés parece haberse distinguido por ello entre omgekeerde Wereld y verkeerde Wereld). Tomados por separado, no todos los motivos del mundo al revés contienen clasemas incompatibles: en ocasiones, atendiendo a la relación entre esos módulos y la realidad, nos hallaremos más bien ante hipérboles de dinámicas sociales históricamente determinadas, como el rico que sirve al humilde, la mujer fumadora o el varón que realiza tareas domésticas. Pero es importante darse cuenta de que ese funcionamiento semántico parcial está subordinado a un funcionamiento pragmático global de tipo antifrástico: la incompatibilidad semántica de módulos como la mula doctor - la liebre cazadora invita a ver una incompatibilidad pragmática en el noble que sirve al plebeyo o en la mujer fumadora. Estos últimos podían ser en el siglo XVIII manifestaciones más o menos extremadas de los nuevos usos sociales, pero en el mundo al revés se nos presentan como lo que no es, o no puede ser, o no debe ser.

Es, pues, la lógica modular, paratáctica, del mundo al revés la que iguala como teóricamente imposibles las contravenciones de la ley natural y las de los usos sociales, la que naturaliza estos últimos y propicia que se perciba como antífrasis lo que, en otro contexto, quizá no pasaría de hipérbole. David Kunzle, en uno de los artículos más luminosos que se han publicado sobre este asunto, propone un ejemplo claro de ello: el grabado de Bruegel sobre el heno que persigue al caballo, en cuyo segundo plano puede verse cómo una mujer persigue a un hombre con intenciones poco santas ${ }^{42}$. Una mujer que tome la iniciativa en la seducción sería - conforme al lema en dialecto flamenco que explica dicho grabado- tan incongruente como una bala de heno que fuera buscando quien la rumie. El mundo al revés consiste, por lo tanto, en un dispositivo retórico que promueve el contagio entre diferentes grados de desorden.

Kunzle afirma en otro lugar que los motivos del mundo al revés se basan en inversiones jerárquicas ${ }^{43}$, lo cual es más cierto en los grabados de La capa azul que en otros, tanto anteriores como posteriores. En general, no puede decirse que la inversión de los módulos pivote sobre un único eje semántico, sino que alterna oposiciones de orden espacial, social, predatorio, de uso, sexual, temporal, generacional, etc.

Todas estas consideraciones permiten comprender la crónica indefinición del mundo al revés: por un lado, responde a una modalidad, la antifrástica, de la cual fue, durante siglos, su principal exponente; por otro lado, su notable estabilidad for- 
mal le da un aire de género; y, en tercer lugar, la facilidad con la que se reduce a un enunciado declarativo («el mundo está revuelto o trastocado») invita a confundirlo con un tópico o lugar común.

\section{LOS ENTREMESES DEL MUNDO AL REVÉS}

En lo que atañe al teatro breve español de los siglos XVII y XVIII, tres piezas se adecuan notablemente al prototipo de mundo al revés como objeto cultural moderno, a eso que podríamos llamar «el mundo al revés propio», en todo conforme a la definición propuesta en las páginas precedentes, y diferenciable de otras manifestaciones del mundo al revés que podríamos calificar de «impropias». Esas tres piezas son la mojiganga calderoniana del mundinovo, otra mojiganga anónima y una tonadilla de Blas de Laserna a la que, por lo que sé, no se le ha prestado aún atención crítica.

La Mojiganga del mundinovo ha sido estudiada y editada por Fernando Plata Parga, quien la fecha en 1658 o 1659. Aparecen en ella primero «dos [personas] que crecen y menguan» ${ }^{44}$; siguen una mujer con espada y un hombre que hila; luego ella se va «al juego» y deja encomendadas a su marido las tareas domésticas. Acto seguido entra una pareja de actores bailando cabeza abajo. Les suceden dos damas que se baten por un hombre afeminado. Viene después el pasaje ya comentado sobre cómo son las mulas, y no los doctores, quienes tratan a los enfermos -lo que tiene por efecto hacerles vivir largos años-, mientras que la función de los médicos ha quedado reducida a la de caballerías. Cierra la mojiganga una escena de toreo al revés, en la cual el picador cabalga a lomos de un toro y rejonea un borrico. Como puede observarse, Calderón se atuvo escrupulosamente al principio estructural de la parataxis de motivos paradójicos. Recordemos de pasada que el motivo del asno que cabalga sobre un hombre, muy frecuente en la estampa popular, tenía un ilustre precedente literario en el capítulo 78 de La nave de los necios, de Sebastian Brant (1494).

El segundo texto es una mojiganga anónima que no conoceríamos si Francisco Barbieri no la hubiese copiado a mano; se conserva en la Biblioteca Nacional de Madrid y ha sido editada por Miguel Zugasti, primero, y por Ramón Martínez, después. Este último, tras estudiar el reparto de actores, la ha fechado en $1697^{45}$. En realidad se trata, como ha demostrado Fernando Plata, de una mera refundición de la pieza de Calderón, en la que el mundinovo ha sido sustituido por un espejo y de la cual se han suprimido algunos pasajes ${ }^{46}$. Los módulos son los mismos.

La tonadilla de Blas de Laserna titulada El mundo al revés (1782) nos presenta, por su parte, un desfile de personajes con el cual se demuestra «que en el mundo muchos / andan al revés». Integran la serie un ciego de los que «se ciegan con el oro», un marido afeminado cuya mujer lleva los calzones, otra mujer que manda en casa, un amo convertido en lacayo de sus criados, un médico que mata, una

44. En Plata Parga, 2009, p. 184

45. Martínez, 2007, p. 304

46. Plata Parga, 2009, p. 170. 
«[d]oncellita» viuda y, en fin, un niño que «tiene cien Navidades / y anda tras todas las mozas / por ver si encuentra a su madre» ${ }^{47}$. Hay también un módulo intermedio algo más ambiguo, que dice así:

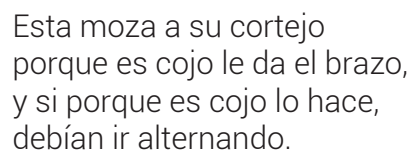

El tullido que ayuda al inválido puede considerarse una variante del motivo emblemático (y bíblico) del ciego que guía a otro ciego, pero el hecho de que el auxilio se preste dentro de la práctica dieciochesca del cortejo hace aflorar otras connotaciones e invita a interpretar el verbo «cojear» en un sentido lato de doblez, engaño e imperfección que recogían ya diccionarios como el de Autoridades (1729) y el de Terreros (1786).

Esta tonadilla escénica presenta la particularidad de aportar explicaciones sobre la conducta incongruente de algunos de sus personajes: el amo está al servicio de sus criados porque ha dejado de pagarles, quedando en deuda con ellos, y la viudita es aún doncella porque «se casó por poderes». Hechas estas precisiones, se observa que solo en el niño-abuelo hay auténtica paradoja semántica: los demás módulos pueden ser las figuras antitéticas de un orden ideal, pero comparados con la sociedad dieciochesca no constituyen tipos antifrásticos, sino fragmentos caricaturescos, hiperbólicos, de un orden social en crisis.

Existe otro subcorpus de piezas que suelen relacionarse con el mundo al revés, y que en ocasiones se identifican con títulos que remiten explícitamente a esta modalidad, pero que, como pone en evidencia un análisis cauteloso, responden de manera menos exacta - con menos propiedad- al esquema retórico presentado. En Las carnestolendas de Calderón, por ejemplo, unas jóvenes tratan de celebrar el carnaval con la representación de una comedia, aunque su padre, un viejo octogenario muy avaro, no les da permiso. Ayudadas por el galán de una de ellas (que ejerce de gracioso) y tomando como pie forzado las expresiones idiomáticas que el viejo profiere, las muchachas se disfrazan, lo insultan y le recriminan su usura. El entremés deviene rápidamente un desfile de personajes proverbiales, entre los que se cuentan el Rey que Rabió, Perico el de los Palotes o la dama Quintañona. Y es solo tras una alusión a los tiempos de Maricastaña cuando el viejo dice:

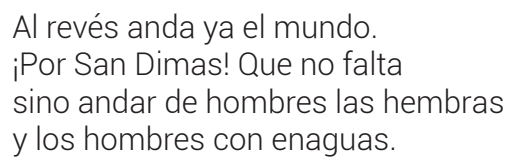

Sale entonces, conforme a la acotación, un actor disfrazado «la mitad mujer, y la otra mitad de hombre, puesto al revés, y andando hacia atrás», y dice lo siguiente:

47. BNE, Ms. 14064/36. Se reproduce parcialmente, modernizada, en el libreto de un disco compacto titulado El mundo al revés e interpretado por La Dispersione (Enchiriadis, 2009). 


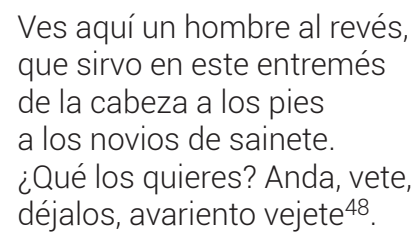

Como es patente, el entremés de Calderón tiene un funcionamiento temático parecido al del cuadro de los Proverbios holandeses de Pieter Bruegel, anterior a él en un siglo. Al igual que en este cuadro, el mundo al revés es solo una de las expresiones idiomáticas representadas. Más que un mundo al revés, lo que aquí se nos da es la enunciación del mundo al revés. Ello no resta encanto a esta sintética alegoría que, aprovechando un brevísimo parlamento, resume varios módulos y diferentes formas de inversión -espacial, trópica y sexual-.

Conviene advertir que en Las carnestolendas la alegoría del mundo al revés entra en escena tras una alusión al reino de Maricastaña, uno de los sinónimos castellanos del país de la Cucaña, que es frecuente relacionar con el mundo al re$v^{\text {vés }}{ }^{49}$. Son varias las piezas de teatro menor español que tratan de esa tierra de la abundancia, entre ellas El talego-niño de Quiñones de Benavente - que la ubica en América- y el anónimo Las brujas fingidas ${ }^{50}$. La más célebre de ellas es, sin embargo, el paso $V$ del Deleitoso de Lope de Rueda, también llamado «paso de Jauja». El bobo Mendrugo es allí engatusado por dos galopines que se le comen a hurtadillas el almuerzo mientras le pintan las excelencias de esa mítica región. Entre manjares y golosinas de todo tipo, Rueda incluye dos inversiones del orden social: en Jauja «pagan soldada a los hombres por dormir» $\mathrm{y}$ «azotan a los hombres porque trabajan». Ello lo emparenta remotamente con el poema que Hans Sachs escribió sobre la misma geografía imaginaria: en Das Schlaraffenland (1530), Sachs no solo describe un espacio de abundancia, sino también un lugar en el que lo razonable es penalizado, la ignorancia es recompensada, se remunera el ocio y resulta rentable contraer deudas ${ }^{51}$.

No obstante, la tematización de Jauja en los pasos españoles se caracteriza menos por la inversión de relaciones naturales que por una abundancia hiperbólica, por un exceso de recursos tal que quedan cancelados los objetivos y las reglas elementales de la vida en sociedad. Hilário Franco Júnior ha creído identificar en esa exuberancia un principio de inversión subyacente: «[c]e serait un monde à l'envers, car ici [en Cocagne] la Nature exerce le rôle de la Culture, en produisant des biens» ${ }^{52}$.

48. Calderón, Las Carnestolendas, p. 153.

49. Madroñal Durán, 1998, pp. 436-442. Los distingue Trousson (1989, p. 35), pero no tanto el resto del volumen en el que se recoge su ensayo, ni Tristan (1980, pp. 38-39).

50. Madroñal Durán, 1998, pp. 443-447; Huerta Calvo, 2001, pp. 123-125.

51. Sachs, Das Schlaraffenland, pp. 76-80. Según Franco Júnior, en las versiones alemanas de este mito habría muchas más inversiones que en sus equivalentes ingleses o franceses: un cojo más veloz que un caballo, dos palomas que descuartizan un lobo, un caracol que mata a dos leones, un caballo elocuente, etc. $(2013$, p. 323).

52. Franco Júnior, 2013, p. 118 
La pirueta lógica, aunque ingeniosa, acaso sea demasiado audaz, ya que solo una parte de los bienes que produce esa tierra portentosa son procesados: no lo son la miel ni la leche que allí corren a raudales, ni los huevos o la canela, y menos aún los metales preciosos que también suelen estar presentes en esas descripciones ${ }^{53}$.

En lo que atañe al Baile de la Casa al revés y los vocablos (1643), sus motivos comportan un grado inferior de imposibilidad. En esta pieza, Quiñones de Benavente presenta una serie de módulos yuxtapuestos. El primero es una mujer que le ofrece dinero al gracioso: se trata del módulo del hombre cortejado por la mujer que, como hemos visto, se encontraba ya en Bruege ${ }^{54}$. Luego salen, sucesivamente, otra mujer que atiende a las visitas mientras su marido pone la olla, una muchacha que se aplica cosméticos mientras su madre barre y friega, una vieja que aprende a bailar y una mujer iracunda junto a un hombre llorón. Tras una serie de trastrueques léxicos, cierran la pieza cuatro hombres travestidos. El orden transgredido aquí es fundamentalmente el orden social -que, como ya hemos visto, resulta menos inmutable que el natural-. El Baile de la casa al revés tiene la estructura de un mundo al revés, contiene módulos conocidos del mundo al revés, será leído casi inevitablemente como una representación del mundo al revés... y, sin embargo, no nos muestra ningún imposible, sino que reúne escenas sintéticas y algo exageradas de desviaciones contemporáneas a la norma social, del mundo como ya empieza a ser. Dada la ausencia de imposible stricto sensu, se puede ver en él una pretensión de gramática social costumbrista, más que una cosmología en negativo.

En cuanto al entremés de Quiñones de Benavente conocido como El mundo al revés, tiene, a pesar de su título, menos conexión aún con el dispositivo retórico homónimo. No encontramos en él módulos paradójicos ni de ninguna otra clase: la pieza trata de alguien que ha olvidado su propia identidad y termina descubriendo que es Juan Rana -es decir, el celebérrimo actor Cosme Pérez-. Quiñones firmó otras dos versiones de esta misma pieza tituladas Baile del mundo y El soldado.

«[P]ara un mundo al revés / las mojigangas se hicieron», declara uno de los personajes del manuscrito de Barbieri, asociando el modo antifrástico al género lúdico y breve. Y, ciertamente, encontramos «mundo al revés» con más o menos propiedad en el teatro menor, mientras que mucho de lo que parece «mundo al revés» en el teatro mayor del Siglo de Oro revela, tras una observación atenta, un mero aire de familia (y recordemos que Wittgenstein empleó el símil de las Familienähnlichkeiten para recalcar la diferencia, y no la identidad categoria|(55).

Algunas comedias del teatro mayor desarrollan módulos tradicionales del mundo al revés, pero el hecho de que la última jornada restablezca el orden considerado natural obliga a preguntase hasta qué punto podemos adscribirlas a la modalidad antifrástica. Ejemplo de ello son varias obras de Tirso, como La república al revés

53. Teodoro Crespo Mas subraya el cariz maravilloso que presentan algunas de esas imágenes de la opulencia (2011, pp. 67-68), pero si lo maravilloso bastase para hablar de «mundo al revés», este sintagma se vaciaría de su significado y de su historia.

54. Roger Chartier y Dominique Julia, en cambio, lo creían surgido a principios del siglo XVIII (1976, p. 52) 55. Wittgenstein, 2016, pp. 277-278. 
(c. 1611), en la que se dice varias veces que el mundo anda al revés, o El pretendiente al revés (<1627), que presenta al espectador amores desordenados, nobles necios y varios trastrueques del protocolo ${ }^{56}$. Solo haciendo un uso extremadamente laxo del concepto podemos considerar «mundo al revés» el enredo, los disfraces, el travestismo o las mistificaciones 57 ; a menos, claro está, que dichas tretas se enderecen a la construcción de un dispositivo antifrástico autónomo dentro de la propia pieza, como ocurre en The Antipodes de Richard Brome (1638). Tampoco tienen la misma construcción retórica ni las mismas implicaciones pragmáticas del mundo al revés los dramas de la honra villana, que encontraban una justificación sociohistórica en los procesos de colonización de la nueva Castilla; se trataba, por lo tanto, de la tematización de una materia polémica, no de la inversión de una doxa hegemónica58.

Han sido relacionados con el mundo al revés numerosos entremeses y comedias sobre mariones, lindos, petimetres y hombres afeminados en general; entre todas esas piezas sobresale Los gurruminos, de Antonio de Zamora, por presentar diferentes variaciones canónicas del módulo de la inversión de los roles de género ${ }^{59}$. También se han estudiado desde esta óptica La mujer que manda en casa y La prudencia en la mujer ${ }^{60}$. Abundan igualmente en las piezas áureas las situaciones que recuerdan más o menos fuertemente otros módulos tradicionales del mundo al revés, como el doctor ignorante o la vieja presumida. Considero, no obstante, que la adscripción de todas ellas al mundo al revés puede contestarse, ya que esos personajes aberrantes suelen ser tipos costumbristas (o protocostumbristas), los cuales, compareciendo de manera aislada, mantienen una relación con la realidad completamente distinta -y casi diría diametralmente opuesta- a la de la antífrasis: se moviliza en ellos el principio sinecdóquico de pars pro toto, según el cual el ejemplar representa a su clase socioprofesional, no a toda su especie o a todo su género (las comedias de marión, verbigracia, no vehiculan un discurso sobre la feminización de todos los varones, sino que materializan y asientan el estereotipo de cierto grupo de hombres). Ha de considerarse, en fin, que cada tipo costumbrista está arraigado en un contexto histórico y geográfico dado, y no dialoga, a diferencia del mundus inversus, con un orden universal transhistórico.

\section{CONCLUSIONES}

Como se habrá visto, abogo por un uso restrictivo de la categoría crítica «mundo al revés», reservándola para las manifestaciones interdiscursivas de esa modalidad antifrástica que sigue un itinerario histórico bastante definido. Estoy convencido de que una decantación conceptual permite apreciar mejor sutiles diferencias estructurales y pragmáticas en documentos culturales de apariencia similar. El mundo al

56. Han sido estudiadas, entre otros, por Hernández García, 1976; Grant, 1979, p. 30; Arellano, 1995.

57. Es lo que ocurre en Gherardi, 2010.

58. Mal que le pese a Helen F. Grant (1979, pp. 30-31).

59. Huerta Calvo, 2001, p. 122; Martínez 2007, pp. 296-303; véase asimismo Zugasti, 2002.

60. Smith, 1986. 
revés moderno presenta una pulsión clasificadora ${ }^{61}$, una pretensión de sistematicidad e interdependencia que debe distinguirse del antiguo principio cómico de la inversión de roles, practicado sin interrupción desde Aristófanes.

El teatro breve constituyó un medio de expresión idóneo para que el mundo al revés se manifestase en todo su esplendor de cosmología apodíctica. No así la novela, por lo que tiene de forma narrativa, polifónica, en la que se teje una urdimbre de causalidades; tampoco el teatro mayor áureo, en el cual, como ha argumentado sagazmente Javier Huerta Calvo, el orden suele restaurarse tras una serie de crímenes, equívocos y altercados ${ }^{62}$. Parece confirmar este mejor acomodo del mundo al revés en las formas dramáticas breves el hecho de que lo hallemos también con sus rasgos paradigmáticos en el género chico de finales del XIX. Recuérdense, por ejemplo, los niños diputados, los viejos presumidos, los guardias encarcelados, las amas oprimidas y las criadas dominadoras que concurren en la famosísima revista La Gran Vía (1886). Federico Gil Asensio y Manuel Moncayo vaticinan en La corte del porvenir (1912) un Manzanares caudaloso y un Madrid invadido por chulapos afeminados, manolas travestidas, gitanas afrancesadas y toreros internacionales. $Y$, de manera menos propia, emparentan con esta modalidad piezas como El mundo nuevo (1861), Otro diablo cojuelo (1870), El mundo al revés (1871), La República femenina (1872) y De Madrid a la luna (1886).

La mojiganga, como siglos después la revista escénica, tiende a una estructura paratáctica que es la típica forma estructural no solo del mundo al revés, sino de muchos productos populares: el pliego de aleluyas, el cartelón que ilustraba los pliegos de cordel, los motivos de cerámica popular y aun los de ciertas labores femeninas en cuadrados o franjas, todos los cuales comparten algunos temas ${ }^{63}$. También los desfiles, las procesiones y algunos carnavales se estructuran conforme a esa misma estética de la yuxtaposición. Mucho se ha insistido, de hecho, en que la palabra «mojiganga» guarda un vínculo etimológico con las vejigas empleadas en festejos populares, y sobre todo en carnaval, a tal punto que admitiría la acepción de «festejo carnavalesco» ${ }^{64}$. Así parece confirmarlo la Mojiganga del mundinovo de Calderón, la cual «se representó en una fiesta de carnaval»65. Obsérvese, no obstante, que estos indicios relacionan el carnaval con las mojigangas en general, y no solo con las del mundo al revés, aunque Ramón Martínez asegure que este es «patrimonio casi exclusivo del carnaval y de la literatura que con él se relaciona» ${ }^{66}$. Si bien es significativo que los Caprichos de Goya se pusieran a la venta un miércoles de ceniza ${ }^{67}$, no lo es menos que la mojiganga del mundo al revés conservada en el fondo Barbieri se proponía desde su subtítulo como idónea «para la fiesta de cualquier fiesta», y no específicamente para carnaval. Consideremos,

61. Babcock, 1978, pp. 27-28.

62. Huerta Calvo, 2001, p. 122

63. Caro Baroja, 1969, pp. 410 y 427.

64. Rodríguez y Tordera, 1983, pp. 59-61; Huerta Calvo, 2001, p. 73.

65. Plata Parga, 2009, p. 165.

66. Martínez, 2007, p. 294.

67. Stoichita y Coderch, 2016, p. 197.

HIPOGRIFO, 8.1, 2020 (pp. 11-31) 
además, que ni los rituales de inversión se restringen al ciclo de carnaval europeo ${ }^{68}$, ni los carnavales comportan siempre nítidas inversiones simbólicas. La noción de carnaval abarca prácticas culturales muy distintas, sin salir siquiera de la geografía española, y las fórmulas de inversión resultan más conspicuas en unos carnavales que en otros (seguramente más en los urbanos que en los tradicionales).

Quiero terminar destacando un aspecto especialmente audaz del mundo al revés en su definición estricta: la tematización crasa, en ocasiones brutal, de relaciones sociales que no suelen ponerse en evidencia, o no de manera tan desacomplejada. El trato tiránico de que son objeto los animales, por ejemplo; la explotación desaforada de los recursos naturales; la opresión autoritaria de los niños; la inscripción social de las mujeres en la intendencia doméstica. Resulta fascinante que la modalidad escogida para constatar estas relaciones de dominación -la antífrasis - constituya al mismo tiempo su abolición textual. De ahí la enigmática ambivalencia del mundo al revés «propio», su capacidad para sustentar lecturas ora conservadoras, ora revolucionarias ${ }^{69}$.

\section{BIBLIOGRAFÍA}

Arellano, Ignacio, «Estrategias de inversión en La república al revés, comedia política y moral de Tirso de Molina», en Tirso de Molina: del Siglo de Oro al siglo xx, ed. Ignacio Arellano, Blanca Oteiza, María Carmen Pinillos y Miguel Zugasti, Madrid, Revista «Estudios», 1995, pp. 9-26.

Avilés Fernández, Miguel, Sinapia. Una utopía española del Siglo de las Luces, Madrid, Editora Nacional, 1976.

Babcock, Barbara A., «Introduction», en The Reversible World: Symbolic Inversion in Art and Society, ed. Barbara A. Babcock, Ithaca (NY) / London, Cornell University Press, 1978, pp. 13-36.

Buezo, Catalina, La mojiganga dramática. De la fiesta al teatro. II, Edición, Kassel, Reichenberger, 2005.

Brückner, Wolfgang, Imagerie populaire allemande, Milán, Electa, 1969.

Caillois, Roger, Les Jeux et les hommes, ed. aumentada, Paris, Gallimard, 1976.

Calderón de la Barca, Pedro, Entremeses, jácaras y mojigangas, Madrid, Castalia, 1982.

Caro Baroja, Julio, Ensayo sobre la literatura de cordel, Madrid, Ediciones de la Revista de Occidente, 1969.

Chartier, Roger, y Julia, Dominique, «Le monde à l'envers», L'Arc, 65, 1976, pp. 43-53.

Cocchiara, Giuseppe, Il mondo alla rovescia, Torino, Bollati Boringhieri, 2007 [1956]. 
Crespo Mas, Teodoro, «En torno a los orígenes empíricos de la utopía como mundo al revés, seguido de un apéndice sobre le etimología del término cocaingne», en Historia y utopía. Estudios y reflexiones, ed. José Luis Hernández Huerta et al., Salamanca, Hergar Ediciones Antema, 2011, pp. 63-82.

Curtius, Ernst Robert, La Littérature européenne et le Moyen Âge latin, Paris, PUF, 1956 [1948].

Delpech, François, «Aspects des pays de Cocagne. Programme pour une recherche», en L'image du monde renversé et ses représentations littéraires et paralittéraires de la fin du XVI $I^{e}$ siècle au milieu du XVII', ed. Jean Lafond y Augustin Redondo, Paris, Librairie Philosophique J. Vrin, 1979, pp. 35-48.

Donaldson, Ian, World Upside-Down. Comedy from Jonson to Fielding, Oxford, Oxford University Press, 1970.

Dorca, Toni, «El mundo al revés: una lectura carnavalesca de Fortunata y Jacinta», Bulletin of Spanish Studies, 84.2, 2007, pp. 193-206.

Dufays, Jean-Louis, Stéréotype et lecture. Essai sur la réception littéraire, Bruxelles, P.I.E. Peter Lang, 2010 [1994].

Dupriez, Bernard, Gradus. Les procédés littéraires (Dictionnaire), Paris, Éditions 10/18, 1984.

Dutli, Ralph, Fatrasien. Absurde Poesie des Mittelalters, Göttingen, Wallstein Verlag, 2010.

Eagleton, Terry, The Event of Literature, New Haven / London, Yale University Press, 2012.

Fortunati, Vita, y Zucchini, Giampaolo, Paesi di cuccagna e mondi alla rovescia, Firenze, Alinea, 1989.

Franco Júnior, Hilário, Cocagne. Histoire d'un pays imaginaire, s. I., Les éditions arkhê, 2013 [1998].

Gherardi, Flavia, «Periandro y Auristela: su contribución a la teoría y a la práctica del "mundo al revés"», en Actas del XVI Congreso de la Asociación Internacional de Hispanistas: Nuevos caminos del hispanismo, coord. Pierre Civil y Françoise Crémoux, Madrid / Frankfurt am Main, Iberoamericana / Vervuert, vol. 2 (CD-ROM), 2007, s. p.

Gracián, Baltasar, El Criticón, ed. de Miguel Romera Navarro, London, Oxford University Press, 1938 [1651-1657].

Grant, Helen F., «El mundo al revés», en Hispanic Studies in Honor of Joseph Manson, ed. Dorothy M. Atkinson y Anthony H. Clarke, Oxford, The Dolphin Book, 1972, pp. 119-137.

Grant, Helen F., «The World Upside-down», en Studies in Spanish Literature of the Golden Age, ed. R. O. Jones, London, Tamesis, 1973, pp. 102-135. 
Grant, Helen F., «Images et gravures du monde à l'envers dans leurs relations avec la pensée et la littérature espagnoles», en L'image du monde renversé et ses représentations littéraires et para-littéraires de la fin $d u X v I^{e}$ siècle au milieu du XVII', ed. Jean Lafond y Augustin Redondo, Paris, Librairie Philosophique J. Vrin, 1979, pp. 17-33.

Guillén, Claudio, Entre lo uno y lo diverso. Introducción a la literatura comparada (ayer y hoy), Barcelona, Tusquets, 2013 [2005].

Gutiérrez Baños, Fernando, «La figuración marginal en la baja Edad Media: temas del "mundo al revés" en la miniatura del siglo XVI», Archivo español de arte, 278, 1997, pp. 143-162.

Hernández García, Carmela, El tópico del «mundo al revés» en Tirso de Molina, tesis doctoral, New York, University of Columbia, 1976.

Huerta Calvo, Javier, El teatro breve en la Edad de Oro, Madrid, Ediciones del Laberinto, 2001.

Kunzle, David, «Bruegel's Proverb Painting and the World Upside Down», The Art Bulletin, 59.2, 1977, pp. 197-202.

Kunzle, David, «World Upside Down: The Iconography of a European Broadsheet Type», en The Reversible World: Symbolic Inversion in Art and Society, ed. Barbara A. Babcock, Ithaca (NY) / London, Cornell University Press, 1978, pp. 39-94.

Lafond, Jean, y Redondo, Augustin, L'image du monde renversé et ses représentations littéraires et para-littéraires de la fin du XVIe siècle au milieu du XVIIe, ed. Jean Lafond y Augustin Redondo, Paris, Librairie Philosophique J. Vrin, 1979.

Madroñal Durán, Abraham, «Vida y obra del licenciado Cosme Gómez de Tejada y de los Reyes (1593-1648)», Revista de Filología Española, 71.3-4, 1991, pp. 287-316.

Madroñal Durán, Abraham, «"La tierra de Jauja" en entremeses barrocos», en II Congreso Iberoamericano de Teatro: América y el teatro español del Siglo de Oro, ed. Concepción Reverte Bernal y Mercedes de los Reyes Peña, Cádiz, Patronato del Festival Iberoamericano de Teatro de Cádiz / Servicio de Publicaciones de la Universidad de Cádiz, 1998, pp. 435-447.

Martínez, Ramón, «Figurones afeminados en el teatro breve del Barroco. Estudio y edición de la mojiganga anónima El mundo al revés», en El Figurón. Texto y puesta en escena, ed. Luciano García Lorenzo, Madrid, Fundamentos, 2007, pp. 293-319.

Martínez González, Jesús María, «Ediciones en español de imaginería popular europea durante el siglo XIX», en Literatura popular. Imágenes e ideas: la imaginatura, Madrid, Fundación Joaquín Díaz, 2012, pp. 4-45 [edición digital].

Menetti, Elisabetta, «El mundo al revés en el siglo XVI», en Mapas de la literatura europea y mediterránea. De los orígenes al Renacimiento, ed. Gian Mario Anselmi, Barcelona, Crítica, 2002, pp. 453-472. 
Navarro Peiro, Ángeles, «El mundus inversus ('olam hafuj) en el Séfer ha-mešalim de Ya'acob ben El'azar de Toledo», en Judaísmo hispano. Estudios en memoria de José Luis Lacave Riaño, ed. Elena Romero, Madrid, Junta de Castilla y León / CSIC, vol. I, 2002, pp. 209-215.

Palla, Maria José, «O parvo e o mundo às avessas em Gil Vicente - algumas reflexões», en Temas Vicentinos. Actas do Colóquio em torno de obra de Gil Vicente, Lisboa, Icalp, 1992, pp. 87-100.

Pla Vivas, Vicente, «El mundo al revés. Lecturas iconográficas sobre un grabado de Antón Wierix contra el dominio de Felipe Il», Boletín de Arte, 20, 1999, pp. 67-86.

Plata Parga, Fernando, «Mundinovos y espejos deformantes: el mundo al revés en una mojiganga inédita de Calderón», Criticón, 106, 2009, pp. 161-192.

Quiñones de Benavente, Luis, Colección de Entremeses, loas, bailes, jácaras y mojigangas desde fines del siglo XVI a mediados del XVIII, Madrid, Bailly-Baillière, 1911 (NBAE, 18), tomo I, vol. 2.

Redondo, Augustin, «Monde à l'envers et conscience de crise dans le Criticón de Baltasar Gracián», en L'image du monde renversé et ses représentations littéraires et para-littéraires de la fin du XVI e siècle au milieu du XVIIe, ed. Jean Lafond y Augustin Redondo, Paris, Librairie Philosophique J. Vrin, 1979, pp. 83-97.

Riandière la Roche, Josette, «La satire du "monde à l'envers" et ses implications politiques dans la Hora de todos de Quevedo», en L'image du monde renversé et ses représentations littéraires et para-littéraires de la fin du XVIe siècle au milieu du XVII', ed. Jean Lafond y Augustin Redondo, Paris, Librairie Philosophique J. Vrin, 1979 pp. 55-71.

Rodríguez, Evangelina, y Tordera, Antonio, Calderón y la obra corta dramática del siglo XVII, London, Tamesis Books, 1983.

Romero Tobar, Leonardo, «La descripción costumbrista en los viajes aéreos», Romanticismo 6. El costumbrismo romántico, Roma, Bulzoni, 1996, pp. 285-298.

Sachs, Hans, Meisterlieder, Spruchgedichte, Fastnachtsspiele. Auswahl, Stuttgart, Reclam, 2003.

Sáez Raposo, Francisco, «Del entremés a la comedia: hacia el itinerario de la metateatralidad», Teatro de palabras. Revista sobre teatro áureo, 5, 2011, pp. 29-56.

Salviati, Francesco, Il mondo alla rovescia, Milano, Studio Lapeyre, 1992.

Schaeffer, Jean-Marie, Pourquoi la fiction?, Paris, Seuil, 1999.

Silvestre Salamanca, María del Carmen, «El tópico del "el mundo al revés" en Los sueños de Quevedo», Interlingüística, 15.2, 2004, pp. 1295-1304.

Smith, Dawn L., «Women and Men in a World Turned Upside-Down: An Approach to Three Plays by Tirso», Revista Canadiense de Estudios Hispánicos, 10.2, enero de 1986, pp. 247-260. 
Stoichita, Victor I., y Coderch, Anna-Maria, Le Dernier carnaval. Goya, Sade et le monde à l'envers, s. I., Éditions Hazan [Imp. par Laballery, Clamecy], 2016.

Toschi, Paolo, L'imagerie populaire italienne du Xve siècle au Xx siècle, Paris, Editions des Deux Mondes, 1964.

Tristan, Frédérick, Le Monde à l'envers, s. I., Hachette, 1980.

Trousson, Raymond, «I mondi alla rovescia: finalità e funzioni», en Paesi di cuccagna e mondi alla rovescia, ed. Vita Fortunati y Giampaolo Zucchini, Firenze, Alinea, 1989, pp. 17-36.

VV. AA., Poemas épicos, ed. Cayetano Rosell, Madrid, Rivadeneyra, 1854 (BAE, 29), vol. II.

Wittgenstein, Ludwig, Tractatus logico-philosophicus. Tagebücher 1914-1916. Philosophische Untersuchungen, Frankfurt am Main, Suhrkamp, 2016.

Zugasti, Miguel, «"Poneos ruecas en la cinta": el trueque espadas-ruecas o el itinerario de un motivo burlesco de la tópica del mundo al revés. (Con edición de la mojiganga anónima El mundo al revés)», en Pulchre, bene, recte. Estudios en homenaje al prof. Fernando González Ollé, ed. Carmen Saralegui Platero y Manuel Casado Velarde, Pamplona, Eunsa, 2002, pp. 1443-1477. 